\title{
AC 2007-1232: LATECHSTEP: LOUISIANA TECH UNIVERSITY'S STEM TALENT EXPANSION PROGRAM
}

\section{Kelly Crittenden, Louisiana Tech University}

KELLY CRITTENDEN is an Assistant Professor of Engineering at Louisiana Tech University. He teaches within the Integrated Engineering Curriculum and Multidisciplinary Senior Design series. His interests are in promoting collaboration across discipline and college boundaries in order to stimulate innovation and advancements in engineering education. Dr Crittenden received his B.S. and Ph.D. in BioMedical Engineering from Louisiana Tech University.

\section{Galen Turner, Louisiana Tech University}

GALEN E. TURNER III received his B.S. from Loyola University, New Orleans, Louisiana, in 1992 with majors in Mathematics and Religious Studies. He received his M.S. and Ph.D. degrees in Mathematics from Louisiana State University, Baton Rouge, in 1994 and 1999 respectively. His current research is in the area of graph minors and computational mathematics as related to a number of interdisciplinary areas of study. In addition to research collaboration, Dr. Turner has served as an educational consultant for centers in Texas and Louisiana, and he is an active member of the Leadership Team for Undergraduate Programs at Louisiana Tech University.

\section{Alicia Boudreaux, Louisiana Tech University}

ALICIA D. BOUDREAUX works as the Student Success Specialist at LA Tech University's College of Engineering \& Science. She advises and supports students, helping to connect them to resources across campus. She also visits with prospective students and their families about the undergraduate engineering and science programs. She has a B.S. in Mechanical Engineering from LA Tech University and an M.S. in Educational Administration from Baylor University.

\section{James Nelson, Louisiana Tech University}




\section{TechSTEP: Stem Talent Expansion Program}

\section{Introduction and Background}

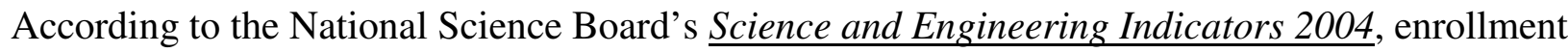
in undergraduate engineering and science programs decreased sharply during the 1980s, followed by slower declines in the 1990s. Since 2000, enrollment numbers have begun to increase again; but the report also indicates that, of those students who do enroll in engineering and science programs, fewer than $50 \%$ earn an engineering or science degree within six years. Clearly, there is a continued need for increased enrollment and retention in science and engineering. In The Science and Engineering Workforce: Realizing America's Potential, the Board strongly recommends national-level action to provide an adequate number of science and engineering graduates to ensure competitiveness in the ever-changing global economy (NSB, 2003). Furthermore, Preparing Our Children (NSB, 1999) urges partnerships between universities and local schools to increase the mathematics and science abilities of high school graduates. TechSTEP directly addresses these concerns.

"the University"'s STEM Talent Expansion Program (TechSTEP) has two major components that will yield increased numbers of graduates in engineering, mathematics, and science. One component is a high school partnership program focused on recruiting new students into our STEM programs, while the other component is a summer enrichment and mentoring program focused on increased retention of first-year college students. The recruiting component is an

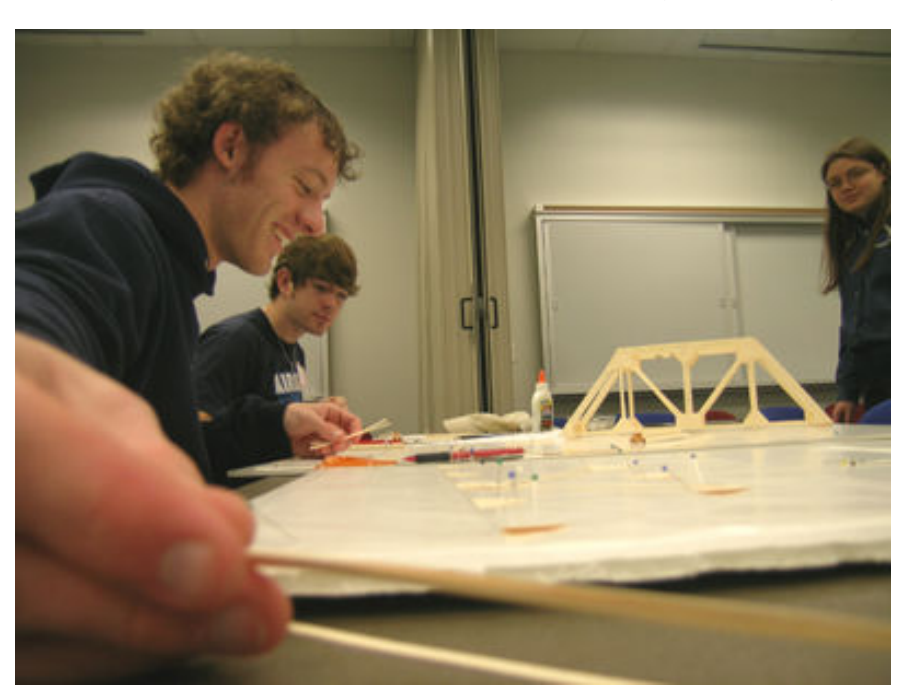

Figure 1. Students working during the Bridges to Engineering pilot. expansion of pilot programs funded by the College, alumni and industry. One of the programs (Bridges to Engineering) was conducted during the 2005-06 academic year and another is being conducted during 2006-07. Successful elements of TechSTEP are adaptable at other schools with similar demographics. The College of Engineering and Science at "the University" has already been very successful at increasing enrollment, retention, and graduation in recent years. Yet, further improvements are attainable. Our overall goal is an annual increase in STEM graduation rates - from approximately 220 students per year to a sustainable 300 students per year - 36\% above our current levels.

At "the University" all STEM programs, with the exception of biology, are housed in the College of Engineering and Science. This has fostered a truly collaborative environment that has led to significant innovations in the classroom and in curriculum development, including our Integrated Engineering Curriculum and Integrated Science Curriculum. We have thirteen undergraduate degree programs including seven engineering programs, two technology programs, computer 
science, mathematics, chemistry, and physics. Having all of these programs under a single administrative unit provides significant advantages for implementing strategies to improve retention and graduation. This also helps us provide students with an unbiased perspective on the opportunities in all programs within the College and will ensure that we do not increase graduation numbers in one area at the expense of another.

\section{The Recruiting Component - High School Partnerships and Discovery Weekends}

The thrust of the recruiting component of TechSTEP is the development of partnerships with key feeder high schools in our area. These partnerships are developed through a series of Teacher Workshops leading to Discovery Weekends for students as shown in Figure 2. The workshops and weekends are designed around a common engineering or science theme for the year. The Teacher Workshops, led by engineering, mathematics, and science faculty at Louisiana Tech, illustrate practical applications of high school mathematics and science topics. The Discovery Weekends include project-oriented, hands-on engineering and science activities following the theme of the Teacher Workshops. The culminating Discovery Weekend includes a design competition in which students apply knowledge gained throughout the year. Students who participate in this program will have a broader exposure to applications of mathematics and science and will be more likely to choose careers in one of the STEM areas. Improved preparation and motivation will also increase the success of these students in completing an engineering or science degree.

\section{Teacher Workshops}

Teacher Workshops are held three times during each academic year. The goals of the workshops are to demonstrate applications of fundamental mathematics and science topics that can be integrated into high school math and science classes as well as to develop meaningful and engaging student projects for subsequent Discovery Weekends. Based on the interest expressed by a number of master teachers and feedback, we expect the workshops to improve pedagogy in both high school and university classes and increase awareness of student preparation. Each workshop is conducted by a team of "the University"'s mathematics, science, and engineering faculty. The goal is to build interdisciplinary teams of university faculty and high school teachers who together develop engineering and science explorations

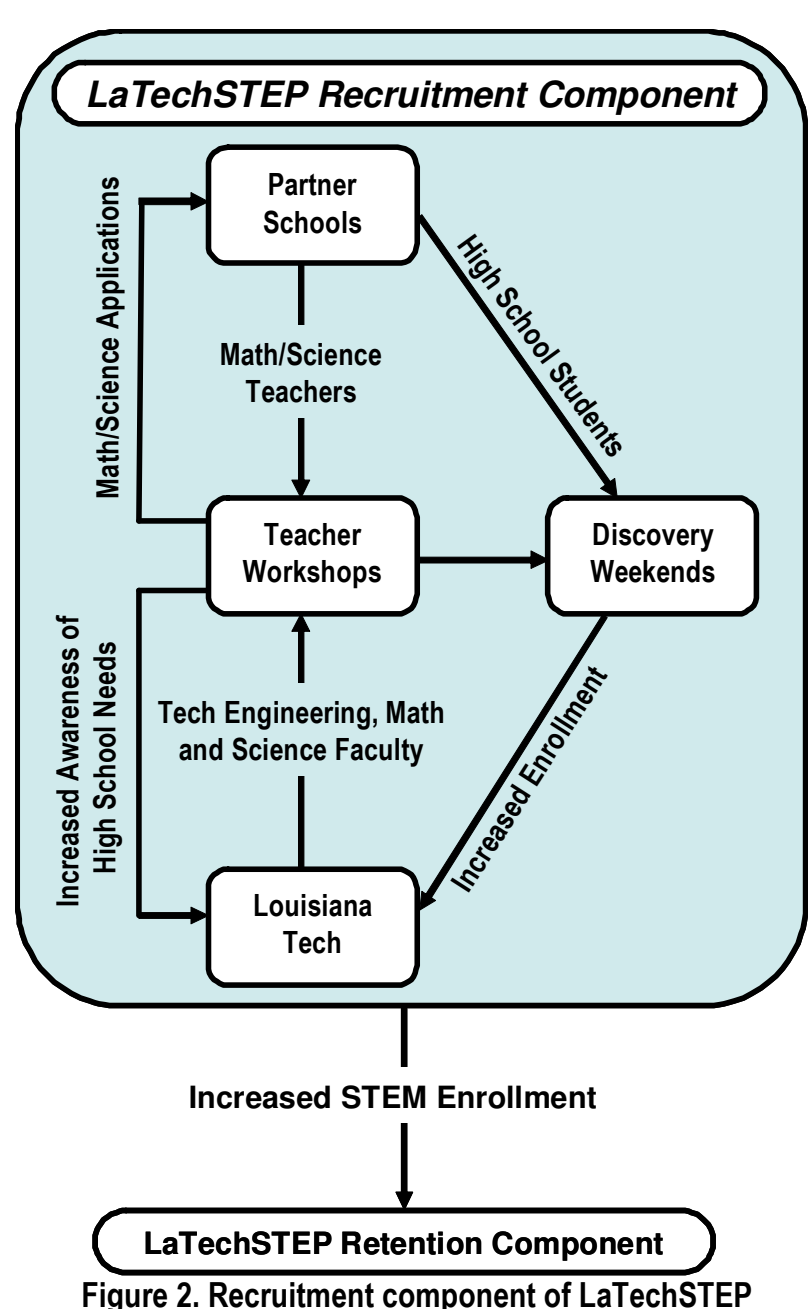

Figure 2. Recruitment component of LaTechSTEP 
and design projects for the subsequent Discovery Weekends. During these preparations, connections between national content standards and the mathematics and science showcased in the workshops is identified and discussed.

\section{Discovery Weekends}

Discovery Weekends are held one to two weeks after each Teacher Workshop. The interdisciplinary teams of high school and university faculty formed during the Teacher Workshops conduct the Discovery Weekends along with college student aids. The primary goal

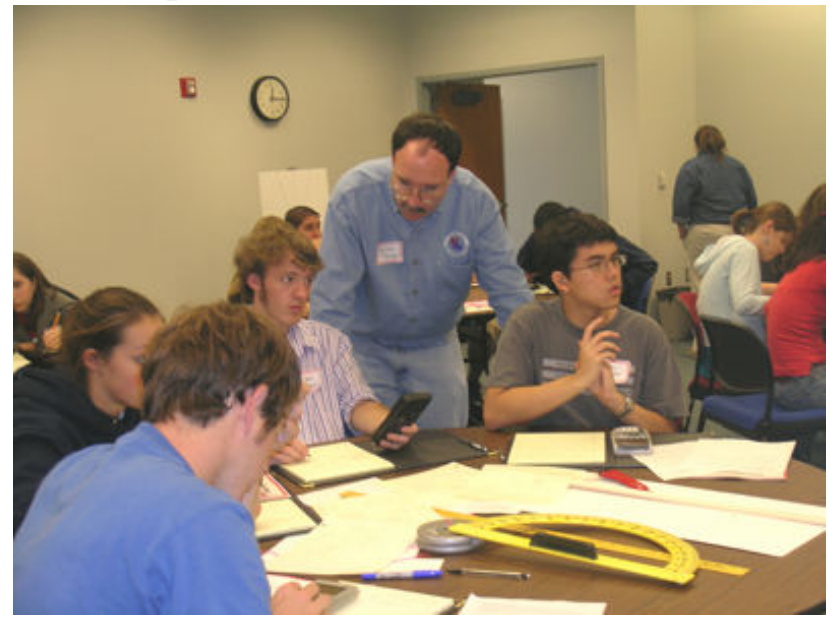

Figure 3. Discovery Weekend problem session of the Discovery Weekends is to motivate high school students to consider mathematics, science, and engineering majors in college. The team approach involving both high school and university teachers and the integration of topics sets our project apart from the more traditional high school weekend science camps. This collaboration between TechSTEP faculty and high school teachers maximizes the benefit to the students by having both their regular teachers and university faculty directly involved in their projects. It will also serves as a model for the students by effectively demonstrating how diverse teams can often provide better solutions to problems.

One teacher wrote:

"I am so excited to think about the possibility of teaching students that have had a real hands-on experience."

Another teacher put it this way:

"One of the questions that students often ask is 'when am I ever going to use this?' Some ask a similar question, 'what can you do with a math or science degree besides teach?' This project will help answer these questions for my students."

One principal commented about their teachers being excited about the project:

"When these teachers learned that Tech was planning this project, without hesitation, they wanted to participate. In fact, they already have ideas on how to reach out to other schools in our system with what they believe they will learn in this project. . . . Collaboration of our faculty with Tech faculty for the duration of the project is progressive and indicates that we are serious about ways to increase learning. . . . Our curriculum department also is highly in favor of this venture." 


\section{Program Impact}

The long-term relationships established with area high school teachers has as much impact on increasing engineering and science enrollments as other aspects of the project. During the first full year of NSF support (2007-08 academic year), we will begin the Teacher Workshops and Discovery Weekends with six key feeder schools in our region. These schools have already been contacted and have enthusiastically agreed to participate in the TechSTEP program.

The schools who have agreed to participate in this project represent a diverse student population from "our state". Two of the schools are located approximately 70 miles away from the university; two are located approximately 35 miles away; one is in a rural area; and one is local. One of the schools is a magnet high school and all have a high proportion of minority students ranging from $27.3 \%$ to $60.2 \%$.

In each of the first three years of NSF support, an average of four teachers and ten students from each school will participate in the program. Therefore, this program will directly engage 24 teachers and 60 students each year. In year four we will broaden our focus by asking each of these schools to mentor another school, thereby expanding the program to 12 schools resulting in 48 teachers and 120 students participating each year. In addition, TechSTEP will indirectly increase STEM enrollments through long-term involvement of teachers and interaction between participating students and their classmates at school. In order to maintain an appropriate level of interaction as we expand from six to twelve schools, we will run two parallel sets of teacher workshops and Discovery Weekends.

Thank you for doing the TechSTEP program. The first Saturday was exciting and interesting and I am looking forward to the next two. I am a senior and will be sending my application to Tech within the next couple of days. I am very interested in becoming a Civil Engineer.

-Seth Bond, Airline High School Senior (TechSTEP pilot participant 2005-06)

LaTechSTEP targets students who have shown an aptitude for math and science but need additional encouragement to consider a STEM discipline as a career choice. Participating teachers select these students based on their personal experiences with them.

"Allowing the high school teachers to select a few students from their classes gives us the ability to identify the students best suited for this program, the ones who are capable but need more encouragement. It will also encourage younger students to do their best so that we will pick them for the next year's program."

-Theresa Stephenson

(TechSTEP master teacher)

\section{Recruiting Component Timeline}

A timeline for the recruiting component of the TechSTEP project is shown in Figure 4. As mentioned earlier, a TechSTEP pilot program was conducted during the 2005-06 academic year with 24 high school students, 3 teachers, 4 faculty and 3 college student mentors. This pilot significantly impacted the structure of TechSTEP. During the pilot phase of Bridges to 
Engineering, it became apparent that interaction with a small group of teachers was necessary in order to adequately tailor the engineering material for high school students. As a result, we determined that the three TechSTEP projects should be piloted with a single school prior to fullscale implementation. The pilot program for the second project, Fuel Cells for Tomorrow, began in the fall of 2006. Beginning fall of 2007 we will pilot the third project which will be focused on either biomedical or nanosystems engineering.

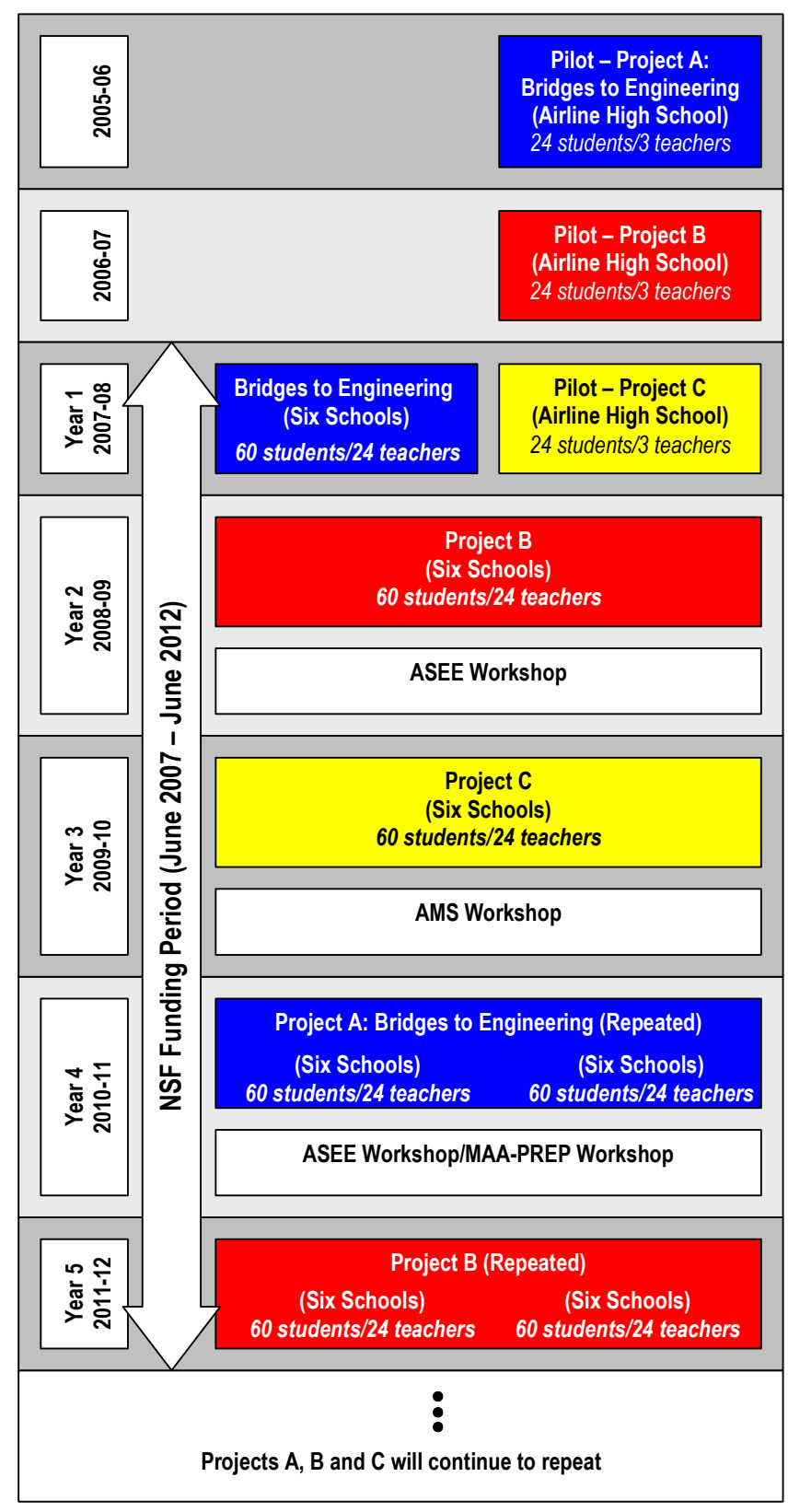

Detailed Example Plan for Project A: Bridges to Engineering

During each year of the program, there are three Teacher Workshops (2 days each) and three Discovery Weekends (one day each). One workshop and Discovery Weekend will be held each quarter (Fall, Winter and Spring). The workshops/weekends will share a common theme for the year. The first year's theme was Bridges to Engineering, a topic that encompasses engineering aspects of bridge design as well as team skills, creative problem solving, and career exploration.

The goal of TechSTEP is to develop material that will pique student interest and show the importance and relevance of both mathematics and science. Experiences indicate that topics which utilize hands-on activities and lead to a design competition will motivate students. We have experience developing this type of educational material at the college level for statics and mechanics of materials. We chose the theme of Bridges to Engineering for the first project because the design of bridges serves as a good application of algebra and trigonometry, is very hands-on and intuitive, gives an excellent introduction to engineering design and easily leads to a design competition. 
A detailed plan for Bridges to

Engineering is shown in Figure 5. Some of the topics, such as team building, creative problem solving, and career exploration will be consistent from one year to the next. However, the presentation of these topics will vary from year to year. For example, there are numerous team building activities from which we may select. We have been successful using ropes course exercises in our freshman curricula for developing team skills and creative problem solving ability. We use variations on these team building activities in Bridges to Engineering, and we will vary the team building activities in subsequent years. The career exploration portion of the workshops and weekends includes presentations by a variety of professional engineers and scientists from the region.

Hands-on experimentation and active learning are used to support the technical topic for a given year. For example, in Bridges to Engineering the design of a small truss is used to demonstrate basic statics and mechanics of materials concepts such as force balance compression loads. Both of these topics are excellent applications of algebra and trigonometry concepts and are fundamental to the design of a bridge. These concepts are woven throughout the program.

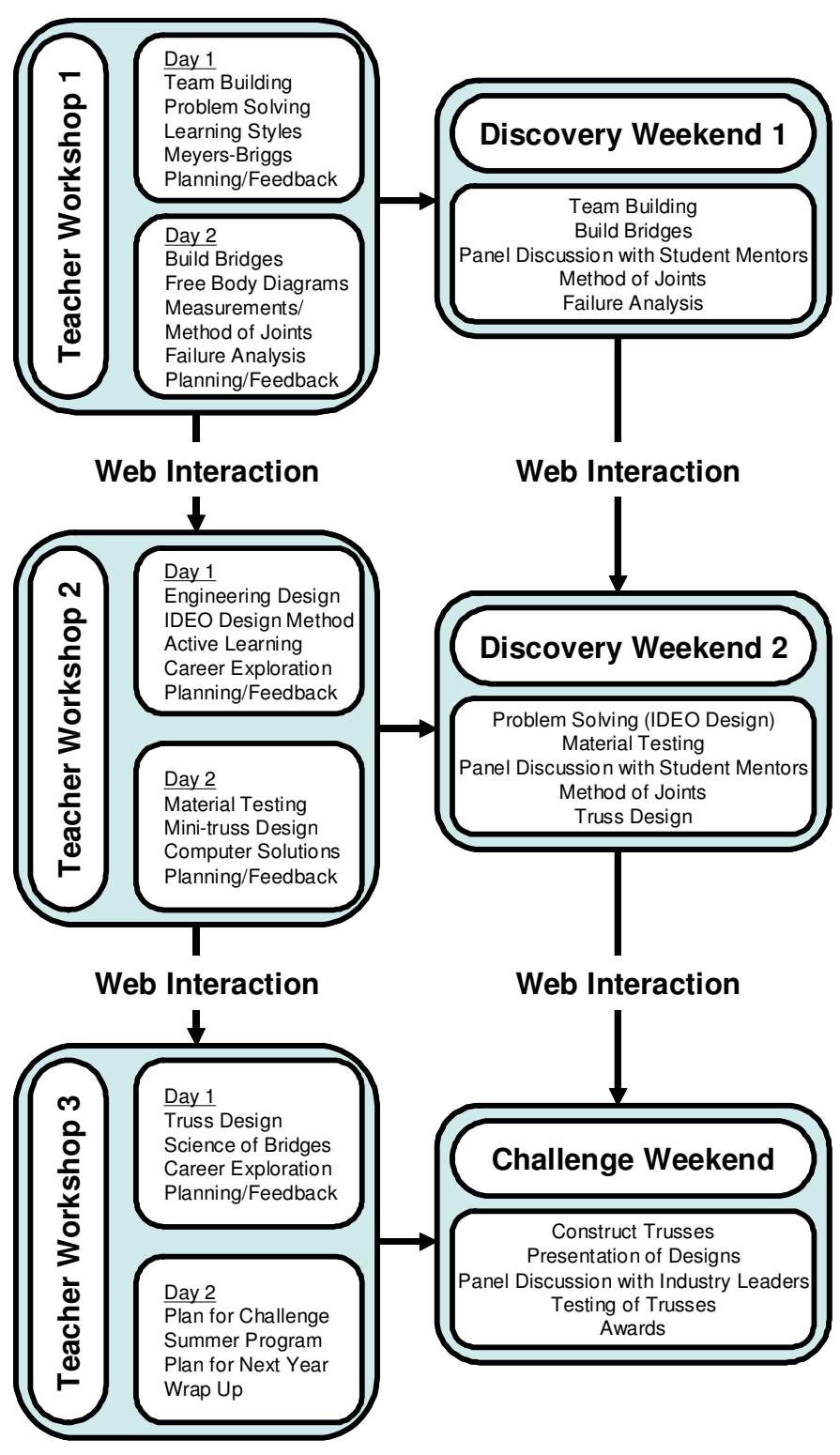

Figure 5. Teacher workshops / Discovery Weekend plan Bridges to Engineering

A web site (www.XXXXX.org) was established during the pilot program to facilitate communication between the teachers, faculty and students. Additional resource material available through this website keeps students motivated throughout the year and particularly focuses on the culminating design competition at the end of the year.

The first two Discovery Weekends lead to the final Discovery Weekend (Challenge Weekend) where the students participate in a design competition based on the year's technical theme. Students are divided into teams of no more than five students per team. The Bridges to Engineering theme culminates with the student teams designing and building a scale bridge. The 
teams are given the competition rules and design constraints during the second Discovery Weekend, thereby allowing them time to prepare for the competition.

\section{The Retention Component - Summer Enrichment Program (SEP) and Mentors}

The retention component of TechSTEP includes a Summer Enrichment Program combined with a student mentor program. This program will begin in the Fall of 2007. These programs help prepare students to begin their first year in a STEM area and are followed by academic-year mentoring throughout their first year of study. Students who participate in Discovery Weekends are encouraged to participate, but the program is available to other students as well. Figure 6 illustrates the major aspects of this retention component of TechSTEP.

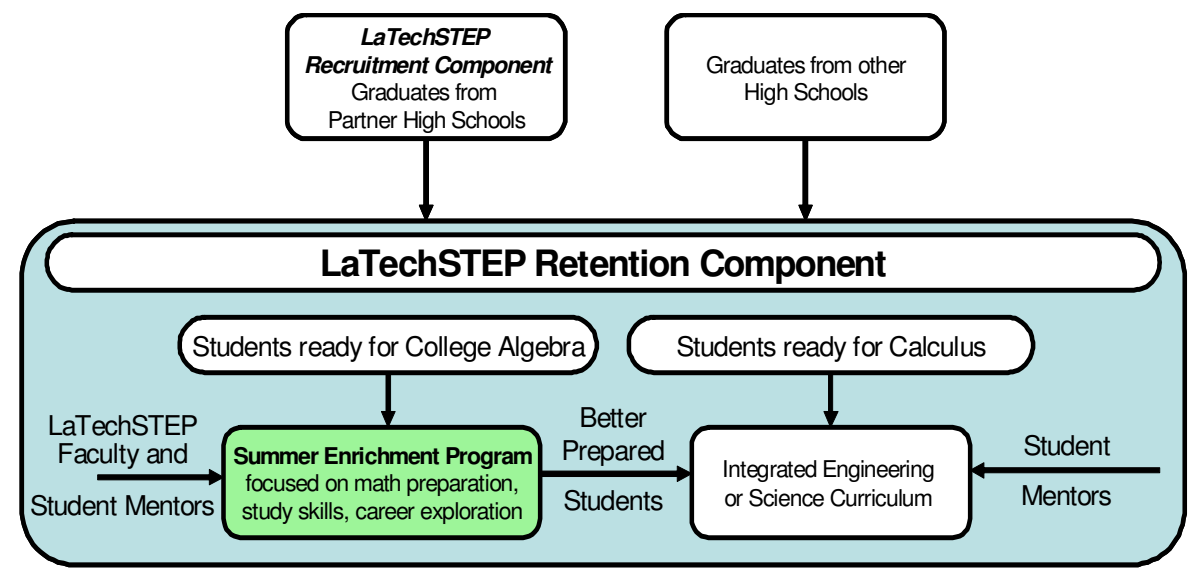

Figure 6. Retention Component of LaTechSTEP

The summer enrichment program will help prepare students to begin our Integrated Curricula in the fall term. All engineering, mathematics, chemistry, physics, and computer science students at Louisiana Tech participate in our Integrated Engineering Curriculum or our Integrated Science Curriculum. These Integrated Curricula are designed to help students make connections between mathematics, science, and engineering. The Integrated Engineering Curriculum is structured such that each quarter students take a block of classes including an engineering class that is directly connected to corresponding mathematics and science classes. The engineering classes were developed to cover fundamental engineering topics, communication and computer skills as well as a design project. The topics covered in the engineering classes are closely connected to the topics covered in mathematics, chemistry, and physics so that all classes reinforce each other. Major revisions were made in the mathematics and science courses to more effectively align the topics in those classes with each other and with the engineering topics. The curriculum also facilitates teamwork since students within a block are all enrolled in the same sections of engineering, science and mathematics classes. Our Integrated Science Curriculum is patterned after the same principles, with all mathematics and science students taking a specified block of classes that reinforce each other.

Approximately half of the students who enroll in "the College" are prepared to begin either of our Integrated Curricula. The remaining students must complete one or more preliminary mathematics course prior to enrolling in Math 240 - Engineering and Science Mathematics I 
(Calculus I). Since Math 240 is in the first block of classes in each curriculum, these students must delay beginning several critically important classes. Though they are able to take other general education courses that are in their curriculum, the prerequisite structure is such that this delay in the first quarter often leads to a full year delay in graduation. Understandably, many students become discouraged. A weak mathematics background, frequently coupled with poor study and time management skills, causes many students to fall further behind, ultimately resulting in withdrawal from the university or a change to a non-STEM degree program.

Data collected over a three year period in our Integrated Engineering Curriculum show a significant increase $(15-20 \%)$ in retention and graduation rates as compared to our previous traditional curriculum. This experience with our Integrated Curricula shows that the application of math and science in an engineering context increases student understanding of these STEM topics and how they interface. We anticipate that these benefits can also be realized by extending this contextual approach back into College Algebra.

Therefore, students who are required to take College Algebra prior to enrolling in Math 240 will be targeted for the Summer Enrichment Program. Based on enrollment statistics at "the University" this represents approximately 125 students per year and includes students who are not prepared to enter our Integrated Curriculum but still have sufficient mathematics skills to be successful. These are the students who will benefit most from the intervention provided by TechSTEP. Moreover, these students will be able to enter our Integrated Curriculum in the fall of their freshman year "on track."

We expect an enrollment of 40 to 60 students in the Summer Enrichment Program for the first two summers, increasing to 80 students per year thereafter. As part of the Summer Enrichment Program, students will enroll in a five-week program during the summer before their freshman year. This program consists of a three-credit-hour college algebra course, enrichment topics, and an optional three-credit-hour general education course such as English, history, sociology or art appreciation. Enrichment topics for the summer program will include study skills, time management, career decision making and acclimation to the University. The Career Development Coordinator for Louisiana Tech's Career Counseling Center has agreed to conduct extensive career decision making workshops for these students. Other activities will include field trips to research centers on campus and engineering and science facilities in the surrounding area in addition to guest lectures by scientists and engineers from these facilities. A sample daily schedule for the program is shown in Table 1.

\begin{tabular}{|l|l|}
\hline \multicolumn{2}{|c|}{ Table 1. Daily schedule for the summer component of FrEP } \\
\hline 8:30-9:30 & Team Building/Creative Problem Solving \\
\hline 9:30-11:0 & College Algebra with Engineering/Science Applications \\
\hline $11: 00-12: 00$ & Enrichment Topics \\
\hline $12: 00-1: 00$ & Lunch \\
\hline $1: 00-2: 30$ & Optional General Education Course \\
\hline $3: 30-5: 00$ & Study Sessions with Mentor Tutoring \\
\hline $6: 30-$ until & Evening Study Sessions \\
\hline
\end{tabular}


Each section of college algebra will be supported by two student mentors. One of the responsibilities of these mentors will be to conduct daily study sessions adapting the Supplemental Instruction (SI) model. SI is an academic assistance program that utilizes regularly-scheduled study sessions directed by trained peer student mentors (http://www.umkc.edu/cad/si). To date, SI has been implemented in hundreds of colleges and universities and has been extraordinarily successful as detailed in well over 400 publications annotated on the SI web site. TechSTEP goes beyond the traditional SI model by creating an environment where cooperative learning communities will emerge. The mentors will not only help students to integrate course content and learning/study strategies, but will also serve as role models and help them adapt to college life through non-instructional interactions.

The college algebra course will be team taught by a mathematics professor and an engineering professor and will include engineering/science applications. Additionally, these students will be required to use ALEKS, a web-based individualized learning assistant, to reinforce the algebra course topics. ALEKS uses diagnostic testing to rapidly identify weaknesses of individual students and focuses practice problems in those areas where an individual student needs the most help. The Mathematics Program at "the University" began using ALEKS to increase student retention and success in freshman-level mathematics courses in 2001. Statistical analysis of student performance data indicates that use of ALEKS is highly correlated with student retention/success.

\section{Summary}

TechSTEP aims to recruit and retain students to STEM majors. The students targeted by TechSTEP have shown potential for STEM disciplines, but for various reasons have not indicated a preference for a STEM major in their future college studies. It is our goal to recruit these students through hands-on, real-world applications of engineering while they are juniors and seniors in area high schools. Once at "the University" we will increase the retention of these students through our Summer Enrichment Program. This program will prepare new freshmen engineering students for our Integrated Engineering or Integrated Science Curriculum. 